\title{
Effect of Transport Infrastructure in changing the urban form of a historical city: A case study of Lahore
}

\author{
Ayesha ANWAR, School of Architecture, Harbin Institute of Technology; Key Laboratory of Cold Region \\ Urban and Rural Human Settlement Environment Science and Technology, Ministry of Industry and \\ Information Technology, China
}

Prof. Leng HONG, School of Architecture, Harbin Institute of Technology; Key Laboratory of Cold Region Urban and Rural Human Settlement Environment Science and Technology, Ministry of Industry and Information Technology, China

Dr. Afia Zubair RAJA, Department of Environment and Land use Change, University of the Fraser Valley, British Columbia, Canada

\begin{abstract}
Urban development and transportation are interrelated as transportation networks help in shaping the urban form along with supporting the social, cultural, and economic growth of the city similarly transportation infrastructure is also shaped by the city dynamics. Lahore Metro Bus Service (MBS) is Pakistan's first rapid mass transit project on Ferozepur road with 27 Kilometers long track and 27 bus stations. It is now an integral part of the Lahore so its implications for the urban fabric need to be studied urgently to fully utilize transit service and to strengthen mobility and emerging economies. According to results, (MBS) has improved the accessibility to basic needs and services but the peculiar character of this historical city is ignored due to poor design. The government needs to bring transport agencies, stakeholders, and people together for joint development policy to enhance revenue, ridership and to move towards Transit Oriented Development (TOD).
\end{abstract}

\section{Keywords}

Metrobus Service (MBS), Transportation Infrastructure, Transit-Oriented Development (TOD), Urban Form

\section{Introduction}

Developing countries are confronting several challenges due to massive urbanization and urban mobility issues are some of them(Division et al., 2017). Predominantly mega developing cities are striving with augmented motorization demand because of significant urban growth and consequent urban sprawl along with decrepit public transport systems. So providing an effective public transport system is very critical for policymakers as car ownership is limited and people tend to look for public transport for traveling(Farrell, 2017). Providing a mass transit system (light rail train or high capacity busses) to overcome mobility issues is considered as a nostrum in developing countries due to limited financial and technical resources. The last decades have seen exceptional demand for Bus Rapid Transit (BRT) as an optimal mass transit solution in many developing cities of Asia. According to global BRT data, BRT is 
operating in 170 cities among which 43 are in Asia and is an extension in 55 cities while planned for erection in 121 cities globally(BRT, 2019).

This study aims to explore the capacity of Bus Rapid Transit (BRT) in reshaping the urban structure of a city through a case study of Lahore, Pakistan who is a new participant in the global BRT club. Lahore, the cultural capital of the country, stands among the list of thirty most populated cities of the world and referred to as the major economic, political, transportation, entertainment, and educational hub of Pakistan. Rapid industrialization, motorization, and expansion have resulted in pollution and traffic congestion. Consequently, the Punjab Government took the initiative of designing a rapid mass transit system for the city, with an aim to improve the accessibility, convenience, and ease of travel for a common man. Among seven similar systems proposed in Lahore Urban Transport Master Plan (LUTMP) by JICA, first-line (Green line) Metro Bus System (MBS) started its operation in 2013, while the Second line (orange line) is under construction(Fig.1).

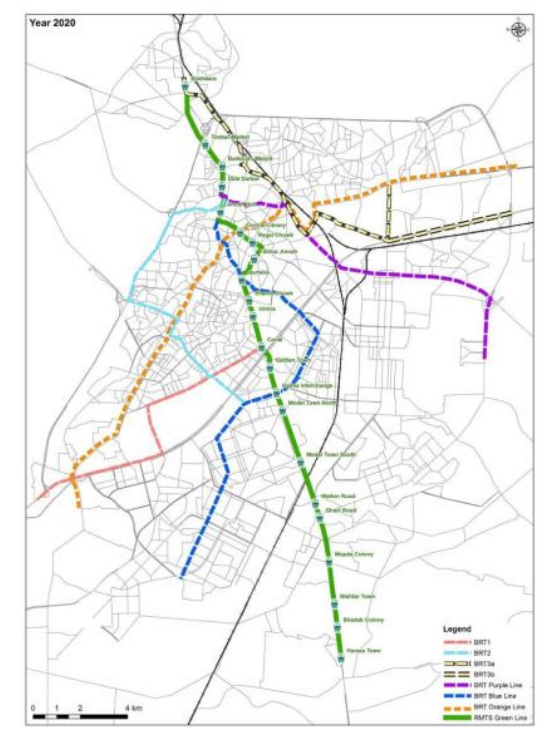

Figure 1. Map of Lahore with proposed Mass Transit lines. Source: JICA Report

As this was the first project of its kind, the impacts of the same on the adjacent built environment were missing. The adjoining urban form evolved sporadically in response to the changing transportation infrastructure, due to the absence of a proper supportive transit-oriented plan it took an ugly shape organically. This paper examines these upshots and complexities, giving a policy framework that can act as a remedial measure to avoid the repetitions of historical transit-related mistakes. At first, literature focusing on the relationship between the urban form of a city and transport infrastructure is included. A later section describes the importance of the study area and the nature of the BRT service. In the subsequent section, analysis is drawn with the help of researchers' observations, google earth images and before \& after shots of area and changes are shown graphically. Finally, some recommendations are made to improve the overall character of the city and to fully utilize transit service and to strengthen emerging economies.

\section{Research Background}

Urban form is associated with the physiognomies of built-up spaces and the cities characters and it is distinct from the urban densities, the land use, and the transport infrastructure. The urban form keeps on evolving with time because cities expand in suburban areas and due to new constructions and redevelopments, variations occur in spatial distributions of urban densities moreover new transport 
infrastructure also affects approachability and land use. Transport infrastructure is an essential component of urban form study as it divides the urban space into well-defined city chunks while connecting them and allows for human activities linking the social, financial, and environmental schemes with the urbanization and populace growth(Prastacos, 2018).

The transportation system and city characters are interlinked and regeneration of an urban area due to it wield multiple impacts on the physical form of the city, even effects the shape and quality of urban life. This impact occurs both directly by the addition of transit infrastructure that changes the whole character of the area as well as indirectly through the developments occurring along the corridor. So strategic planning is required to encourage a sustainable and coordinated approach with the mixing of different travel modes which upsurges convenience, vigorous and active travel, improved air quality, reducing local crowding, and climate change vindication(Suzuki, 2013).

Land use/transportation plans follow an integrated masterplan to meet sustainable options worldwide e.g. Curitiba's Master Plan(Gustafsson, H.R. and Kelly, 2016). Similarly, the Seoul Korea BRT study reveals the change of density from single to dense high rise development along the corridor(Cervero and Kang, 2011). Additionally, Cervero's research reveals that a transit development plan buffers a one-fourth of a mile to half a mile about the Transit station contingent on the walkability index of the neighborhood. Moreover, the findings highlight the importance of introducing zoning and supportively land regulatory alterations before the instigation of BRT initiatives.

In the case of Asia, Bus Rapid Transit is mostly conceived as a transport-only medium by the policymakers with little deviation(Kathuria et al., 2016), consequently followed by limited benefits. usually long-range scritical planning and urban development goals are taken over by near-term engineering and costminimization objectives, resulting in Bus Rapid Transit (BRT) and metro lines being routed and stations sited in areas with minimal development potential. Moreover, it is a huge appeal for politicians who are concerned to launch a new idea in sole political tenancy(Rizvi and Sclar, 2014). These factors need more attention specifically in the south Asian context to determine the possible advantages of BRT with regard to urban development(Cervero and Dai, 2014). So this research aims to further explore the potential benefits of bus rapid transit in concurrence with the city's form by taking the case study of the Lahore Metro bus service(MBS)(Green Line). This was the first line among the seven similar proposed by JICA(JICA, 2012) so these findings will not only be useful for future lines in Lahore \& other cities of Pakistan but also for other developing countries seeking to adopt mass transit systems.

\section{Methodology}

A qualitative approach was used to find out the changes in the urban character of the adjacent development after the implementation of the Lahore Metro Bus Service Plan. Primary fieldwork was conducted by the researchers in 2018 to observe the changes and google earth images (2012) were taken as base maps for comparison.MBS Lahore is a $27 \mathrm{~km}$ long track including an $8 \mathrm{~km}$ elevated section, having 27 bus stations in total among which 18 are At grade stations while 9 are Elevated stations. Eight stations which are dominantly changed due to Metro bus Intrusion, are selected for comparison and analysis. The sample junctions are as follows:

1. Shahdra Station (At Grade) 2. Azadi Chowk Station (At Grade) 3. M.A.O College station (Elevated Station) 4. Canal Station (Elevated Station) 5. Kalma Chowk Station (At Grade) 6. Qainchi Station (At Grade) 7. Chungi Station (At Grade) 8. Gajjumata Station (At Grade)

Comparison is drawn with the help of google earth \& photographs of the particular area (2012 \& 2018), observations of the researcher and changes are marked and the difference is shown graphically. 


\section{Case Study}

Lahore, also famous as the "cultural heart of Pakistan", is the second biggest metropolitan area in Pakistan with a long history of more than 2000 years. According to the census 2017, its population is $11,126,285$ with an annual growth rate of $4.07 \%$ since 1998(PBS, 2018). Previously the city had been governed by Mughal Empire then came underneath British rule in the Indian Subcontinent and after independence in 1947, Lahore became the part of the Islamic Republic of Pakistan. The city reveals a number of historical buildings, mosques, temples, churches, tombs, and parks which makes it a striking traveler place. Lahore has developed several layers now comprising the dense walled city along with less dense nearby urban and suburban areas to the south and southeast side(NESPAK, 2004). At present, it is a lively metropolitan area with various commercial and trade opportunities and an upcoming hub for the technology sector.

The city has changed in the latest years through urban regeneration, heritage restorations, and intransigent infrastructure development. Lahore is formerly known as the "Mughal city of gardens" (Naz and Anjum, 2007) but presently this city has to turn into the sufferer of various challenges like urban decay, the rapid increase in land prices, and escalation. Lahore is much developed with reference to infrastructure(Rana, Bhatti and e Saqib, 2017) even so it overlooks numerous issues as these huge ticket infrastructure projects remain isolated and are being established shortly of an integrated plan or strategy(Alam, 2015).

Considering the case study, the Metro Bus system (MBS) Lahore is Pakistan's first rapid mass transit project with a $27 \mathrm{KM}$ long route in the North-South direction passing through the heart of the city, among which $8 \mathrm{KM}$ segment of the line is elevated. (Fig.2)

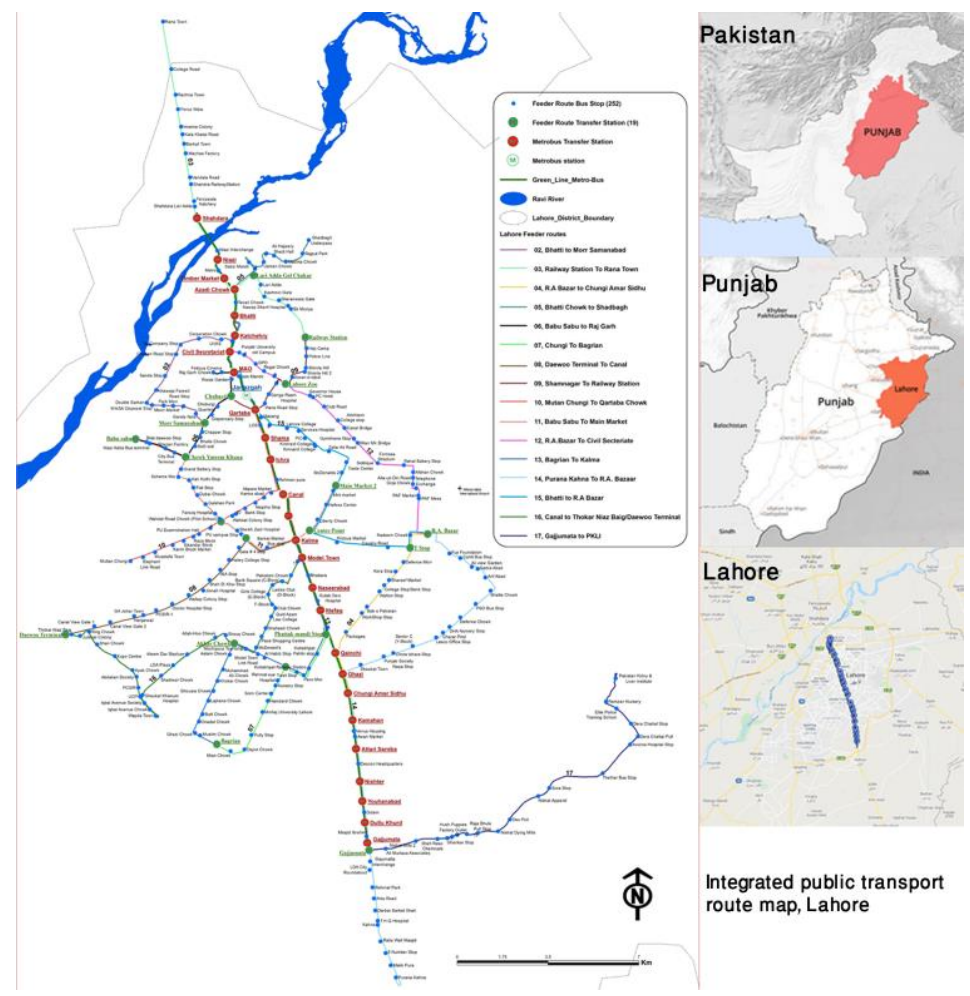

Figure 2.Metro Bus System (MBS) in Lahore (Source: PMA)

Starting from initial sketches to its long laid sections, the whole character of Lahore is changed within 11 months. The route covers various residential and commercial areas through Ferozepur Road, Lytton 
Road, Jain Mandar, MAO College, Lower Mall, Civil Secretariat, Aiwan-i-Adal, Chowk Katchehry (District Courts), Shrine of Hazrat Data Ganj Bakhsh, Niazi Chowk, Ravi Road, and Shahdra town(Fig.3).

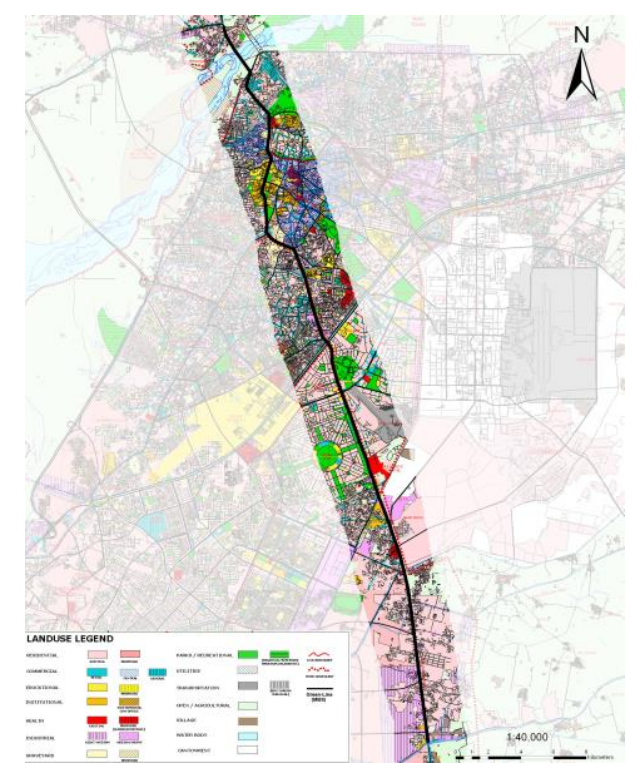

Figure 3. Land-use plan around the Metro bus System(MBS) Source:NESPAK

Construction of MBS Lahore was started in March 2012 and the buses came into service in February 2013. Local \& Turkish expert's team was involved in designing the project and MBS corridor has the following main features(PMA, 2019);

- A $10 \mathrm{~m}$ wide barrier-controlled dedicated corridor

- Pre-board fare collection system

- Passengers can access the platforms through escalators, stairs, pedestrian bridges \& underground, a subway-styled passageway with gated entry and exit through turnstiles

- Presently system runs with 64 articulated buses with a maximum speed of $50 \mathrm{~km} / \mathrm{h}$ and commercial speed is $26 \mathrm{~km} / \mathrm{h}$ at a headway of 2 minutes approximately

\section{Urban From Analysis}

The Lahore is a historical city with many layers and Ferozpur road serves as the city's main artery comprising dozen of residential and commercial zones. The urban form of some of the congested junctions is compact and complex i.e. Shahdra town, Azaadi Chowk, Shrine of Hazrat Data Ganj Bakhsh, Jain Mandar, MAO College, Muslim town Mor, Kalma Chowk, Chungi. Keeping in mind the availability of space for the metro route and allied services, $8 \mathrm{~km}$ of the section is made elevated while the other is at grade. The whole character of the area is transformed in eleven months but the focus remains on the design of hardcore components like station design or route design etc. while the aspect of urban development is absent in the whole design. Urban form analysis of the area is given below;

\subsection{Positive Effects}

\section{Improved accessibility}

MBS is valued by its users and citizen with all its advanced facilities and 180,000 commuters per day ridership is stated by Punjab Masstransit Authority(PMA)(Ahmed, Hafiz Usman and Azeem, 2015). (Kashif 
and Kashif, 2015) Assesses MBS as compared to global leading examples ascribed in The BRT Standards by the(ITDP, 2016) and it ranked as Standard with scoring less than 55 points.

\section{Area Upgradation}

The intrusion of Metrobus has changed the vision of the whole route, at some places it has improved linkages and has created tidiness. Considering Kalma Chowk which is one of the busiest junctions on Ferozpur road with one leg leading towards Qasur and also connecting to Model Town Society. Second leg moving towards Qaddafi Stadium, the third lane linking Barkat market to Gulberg. The urban form of the Kalma Chowk area has transformed a lot with multiple changes in road infrastructure and building uses (Fig.4). Before the intrusion of Metrobus, the famous Kalma landmark was removed and the flyover was added to eradicate the traffic conflicts on Ferozpur road. Kalma station was added under the flyover, buoyed by a pedestrian underpass to access the metro station. In order to link the Barkat market to Gulberg, a vehicular underpass and U-turn was added. Although traveling distance has increased due to flyover and U-turns, the urban form is tidy and hassle-free. (Fig.5)
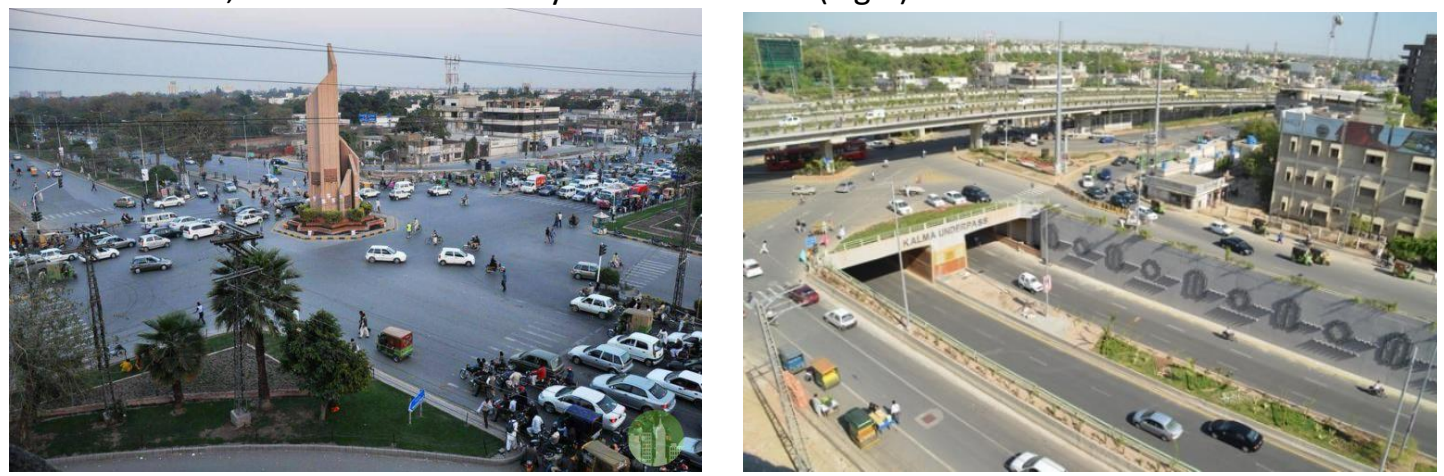

Figure 4. Before and after shots of the Kalma Chowk area (Source:Author)

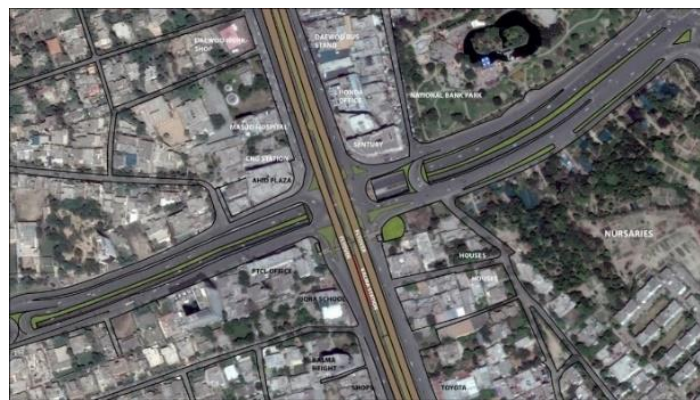

Figure 5. Post Metrobus scenario of Kalma Chowk (Source:Author)

Another noticeable modification is at Qainchi station, important because of the factory areas and surrounding housing communities. Transport infrastructure including at grade metro bus station, pedestrian bridge, and flyovers have changed the whole atmosphere of the area. It involves land acquisition, road widening, and buildings demolition (Fig.6).

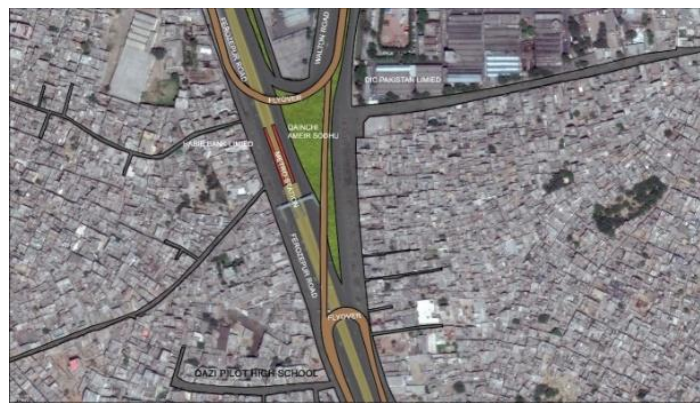

Figure 6.Modifications at Qainchi Station area (Source:Author) 


\section{Views to historical buildings}

Some of the elevated routes along with stations and pedestrian bridges provide beautiful views of many historical landmarks like the Shrine of Hazrat Data Ganj Bakhsh, GC University, Badshahi Masjid, Minar e Pakistan, etc. (Fig.7)

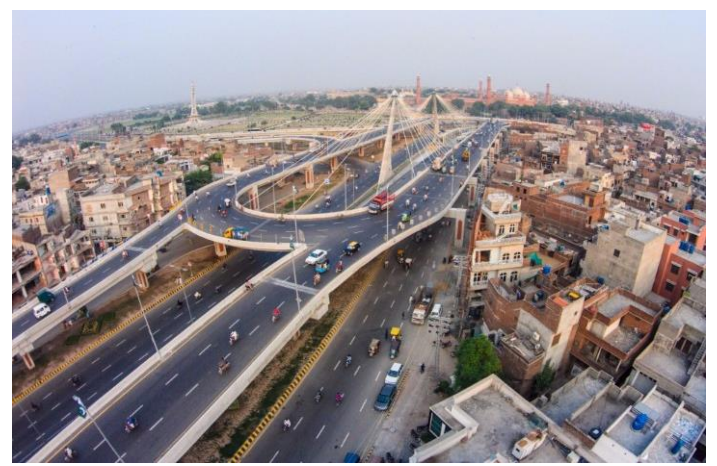

Figure 7. View of Badshahi Masjid \& Minar e Pakistan behind the rotary (Source:PMA)

\section{Potential for future development}

The Metrobus route has generated many areas with potential for future developments and economic growth. Considering MAO college junction which is very evident due to its links to many important roads like Lytton road, Sandha road, and old Anarkali link and many prominent buildings. An elevated station is provided in front of Hailey College and accessed through a pedestrian bridge giving the view of the whole area. The station is connected through two rotaries and a link for future lines. The Orange train is crossing it with an underground passage that is under construction so the area is still undergoing changes and adjustments. Many shops are demolished for the construction of underground passage and have the potential for future dense development (Fig.7).

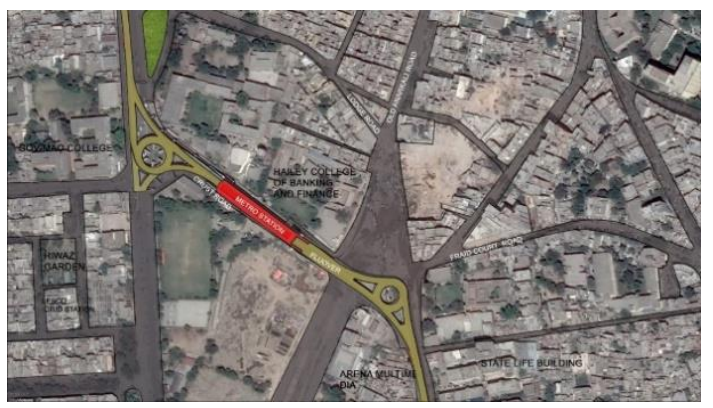

Figure 8. The area under development at MAO College Station (Source:Author)

Another important area is Gajjumata Station where the Metrobus route ends, the area is enhanced after the construction of the metro station. Surrounding vacant land has the potential for future expansion and economic activities (Fig.9).

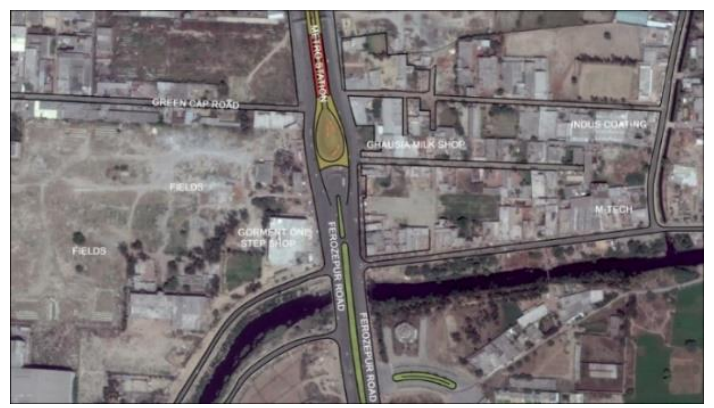

Figure 9. Potential vacant land for future development at Gajjumata Station (Source:Author) 


\subsection{Negative Effects}

\section{Lack of interaction}

A major part of the route is at grade with steel fenced corridor which has divided the city into two parts consequently creating problems for pedestrians and vehicles to access the other side as turning and pedestrian crossings are at a longer distance.

\section{The city's ugly side exposed}

The elevated route has exposed the ugly side of the city to everyone. The rooftop of the most shops are either being used for storage purpose or as leftover space which is exposed now and neighboring houses are facing the privacy issues also (Fig. 10).
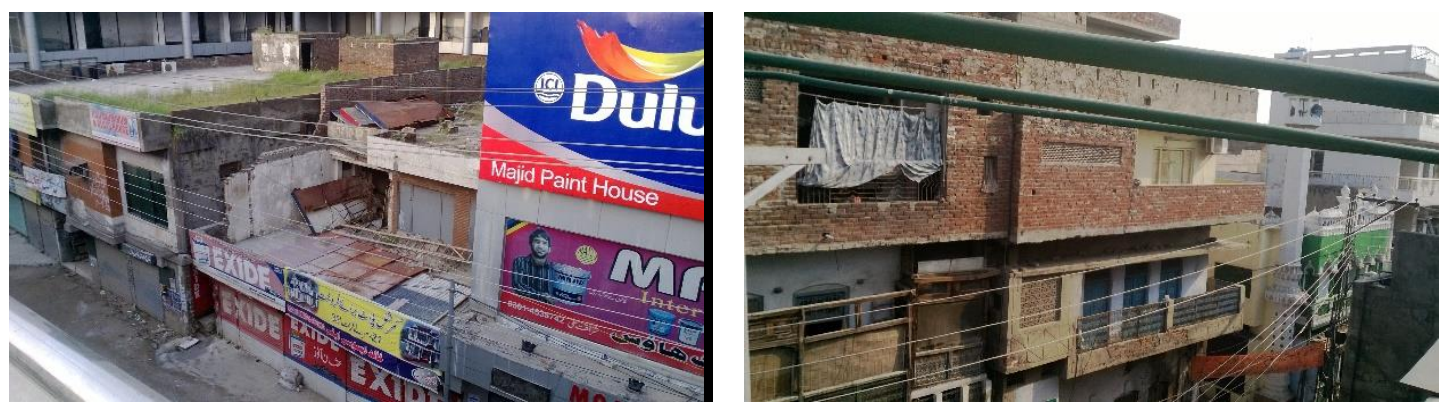

Figure 10.Exposed roofs and facades along the elevated route (Source:Author)

\section{Lack of allied infrastructure}

Due to the lack of allied infrastructure like spaces for paratransit services and pedestrians, the project is serving just for moving people but not comprehending the urban morphology of Lahore. Analyzing the Shahdra station located at the famous Shahdra MOR which works as one of the major entry points to Lahore city while connecting to old Ravi Bridge and Sheikhupura road also. Moreover, it serves as a transfer station for people coming from other cities or riders from the boundaries of Lahore so daily boarding and alighting are high. When comparing the area with the past, many new developments can be seen other than road widening and alignment but due to the absence of proper drop-off space, buses and rickshaws are creating a bottleneck for other traffic. (Fig.11)
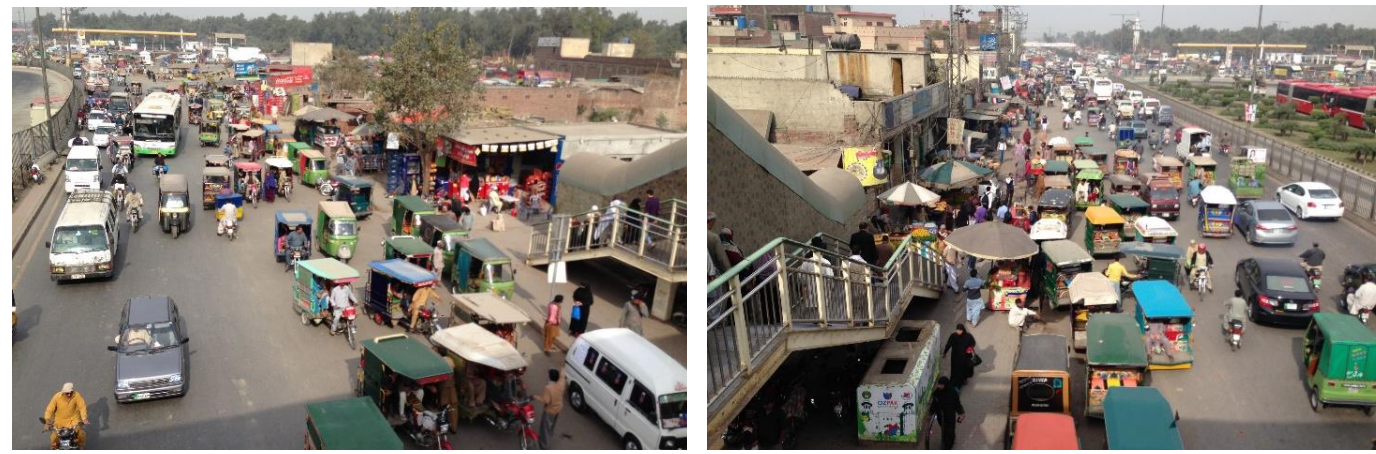

Figure 11. Absence of proper drop off areas at Shahdra Station(terminus) (Source:Author)

A similar problem has been observed at Canal station located at Muslim town MOR which is accommodating traffic coming from the motorway, jail road, and Wahdat road. Metrobus elevated station is induced in the center of the road parallel to the flyover crossing supplemented by a slip lane to access Wahdat Road. Space under flyover is being used for vehicular parking and landscaping. The Station area is surrounded by many educational buildings, residential development in Wahdat colony, and a commercial hub thus becoming one of the busiest metro stations. Pedestrian underpasses are provided at both the ends of the station, these entry points are surrounded by hawkers and chingchi rickshaws 
making it overfilled and choked which needs to be incorporated into space design to improve the place quality (Fig.12).

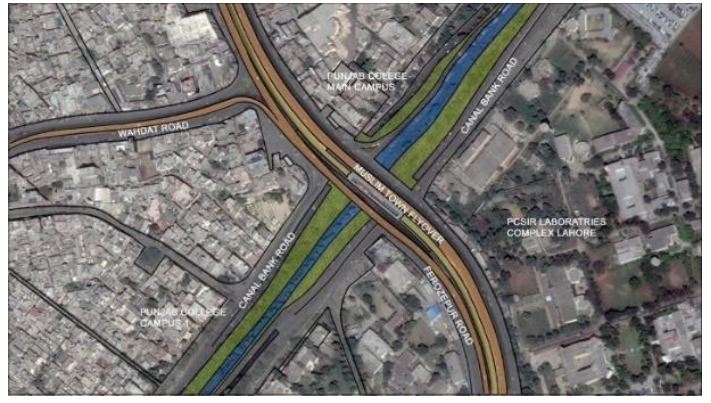

Figure 12. Missing allied Infrastructure at Canal Station (Source:Author)

\section{Visual obstruction \& complexity}

Due to massive flyovers, excessive bridges, and station designs, at many stations transport infrastructure is dominating the whole area thus making urban form complex and in some ways, visually obstructing (Fig 13). Discussing Azaadi chowk station which is among the busiest junctions of Lahore due to Lari Adda, populated walled city area and many monumental buildings like Badshahi Mosque and Minar e Pakistan. The urban fabric of this area has changed a lot after the intrusion of Metrobus. Initially at grade station was introduced at the median along with the pedestrian bridge, later in 2013, a rotary was added to remove traffic congestion and conflicts. Consequently, the overhead pedestrian bridge was replaced by an underground passage for crossings. A chunk of adjacent land was acquired and many buildings along the corridor were demolished.

In addition, this issue has been observed at Chungi station where transport infrastructure is also very prominent therefore making urban form visually enclosed (Fig.14). If we compare the present Chungi junction with its older version we can conclude that the congestion and traffic jam issues are not somewhat resolved, this improvement in its functionality is due to the road widening and rotary intrusion. Noticeable traits of the built environment include the addition of new shops to replace the old ones that were demolished during the metro infrastructure construction. Rotary which is for pedestrians and motorcyclists was added in 2014 after metro bus construction to resolve congestion and traffic issues.
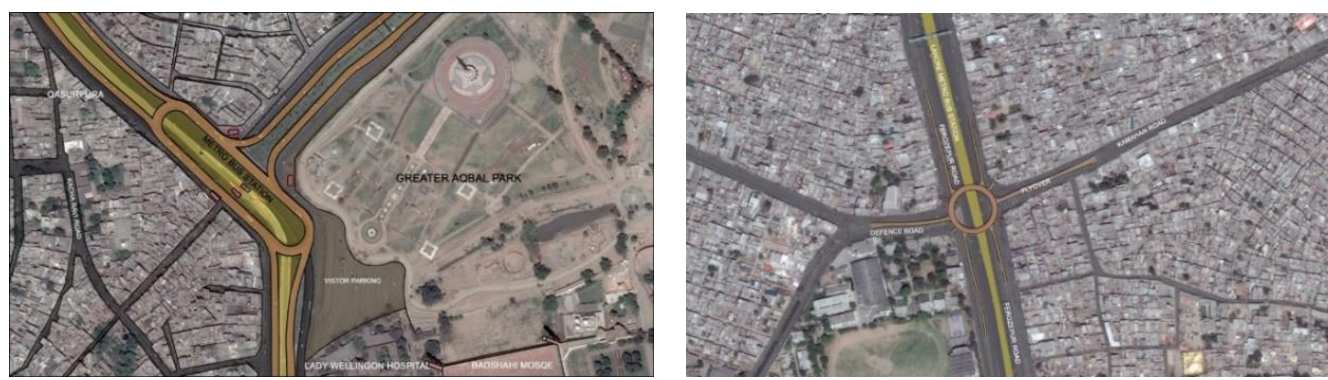

Figure 13. Infrastructure dominating at Azaadi Chowk Station and Chungi Station (Source:Author)
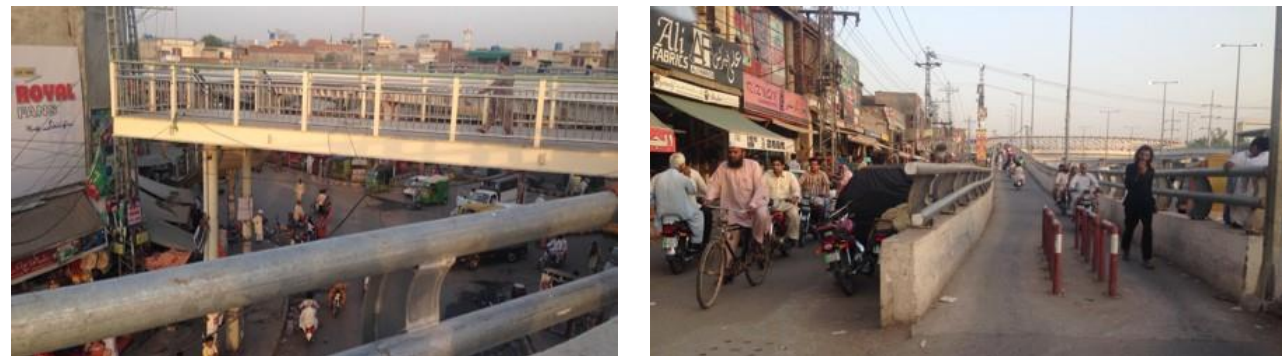

Figure 14. Rotary making urban form visually enclosed at Chungi Station (Source:Author) 


\section{Conclusions \& Recommendations}

Transport infrastructure has influenced the area majorly whether in the form of the ugly steel fence along the entire route or a long winding road; hanging over the heads casting long shadows thus making the urban form complex and visually obstructed. From analyzing 8 important nodes of the MBS route, it is evident that various areas are developed and transformed due to this project and have the potential for generating economic activity and strengthening mobility. The location of the stations has implications for land use and its planning not only around the bus route but in the areas connected to them. Urban green infrastructue is needed to make it hospitable and to soften its image. A joint approach for urban development and transport planning is required to use this mass transit system as a tool for the urban renewal of metropolitan Lahore.

Punjab government needs to bring transport agencies, PMBA, investors, developers, and people together for joint development policy to enhance revenue, ridership and to move towards Transit-oriented development (TOD) containing retrofitting, regeneration, and re-densification of recognized urban cores and promoting the compact, transit-oriented urban expansion. Transit-oriented design is possible when transit investments lead or correspond with regional growth. Since transit is not just about travel but urban life, the provincial government needs to provide financial and technical support to acquire, develop, and hold land or buildings around the MBS route and support the process of mixed land-use, mixed-income housing on these parcels.

\section{References:}

Ahmed, Hafiz Usman and Azeem, A. (2015) Evaluation of System Performance of Metro Bus Lahore.

Alam, A. R. (2015) Failure of urban planning. Available at: https://tribune.com.pk/story/850425/failureof-urban-planning (Accessed: 20 September 2019).

BRT (2019) Global BRT Data. Available at: https://brtdata.org/ (Accessed: 14 April 2019).

Cervero, R. and Dai, D. (2014) 'BRT TOD: Leveraging transit oriented development with bus rapid transit investments', Transport Policy, 36, pp. 127-138. doi: https://doi.org/10.1016/j.tranpol.2014.08.001.

Cervero, R. and Kang, C. D. (2011) 'Bus rapid transit impacts on land uses and land values in Seoul, Korea', Transport Policy, 18(1), pp. 102-116. doi: https://doi.org/10.1016/j.tranpol.2010.06.005.

Division, P. et al. (2017) 'UNITED NATIONS EXPERT GROUP MEETING ON The urban transition and beyond : Facing new challenges of the mobility and settlement transitions in Asia', (September).

Farrell, K. (2017) 'The rapid urban growth Triad: A new conceptual framework for examining the urban transition in developing countries', Sustainability (Switzerland), 9(8), pp. 1-19. doi: 10.3390/su9081407.

Gustafsson, H.R. and Kelly, E. A. (2016) 'Developing the sustainable city: Curitiba, Brazil, as a case study.', in How Cities Will Save the World: Urban Innovation in the Face of Population Flows, p. 81.

ITDP (2016) Institute for Transportation and development Policy. Available at: https://www.itdp.org/library/standards-and-guides/the-bus-rapid-transit-standard/.

JICA (2012) The project for Lahore urban transport master plan in the Islamic Republic of Pakistan : final report ; Vol. 1. -. Available at: http://open_jicareport.jica.go.jp/710/710/710_117_12068110.html.

Kashif, D. and Kashif, R. (2015) 'Evaluation of Lahore Bus Rapid Transit System', (10), pp. 138-148.

Kathuria, A. et al. (2016) 'CIVIL \& ENVIRONMENTAL ENGINEERING | REVIEW ARTICLE A review of bus rapid transit implementation in India', Cogent Engineering, 30(1). doi: 10.1080/23311916.2016.1241168.

Naz and Anjum (2007) 'TRANSFORMATION OF MAIN BOULEVARD , GULBERG , LAHORE : From Residential to Commercial', Journal of research in architecture and planning, 6(2007), pp. 49-61. 
NESPAK, L. (2004) 'Integrated Master Plan for Lahore-2021', Lahore, Pakistan: Lahore Development Authority.

PBS (2018) Pakistan Bureau of Statistics. Available at: http://www.pbs.gov.pk/content/population-sizeand-growth-major-cities.

PMA (2019) Punjab Masstransit Authority. Available at: https://pma.punjab.gov.pk/.

Prastacos, Poulicos and Lagarias, A. (2018) 'Urban Form and Transportation Infrastructure in European Cities', in Data Analytics: Paving the Way to Sustainable Urban Mobility. Springer, pp. 79--88. doi: https://doi.org/10.1007/978-3-030-02305-8_10.

Rana, I. A., Bhatti, S. S. and e Saqib, S. (2017) 'The spatial and temporal dynamics of infrastructure development disparity - From assessment to analyses', Cities, 63, pp. 20-32. doi: https://doi.org/10.1016/j.cities.2016.12.020.

Rizvi, A. and Sclar, E. (2014) 'Implementing bus rapid transit: A tale of two Indian cities', Research in Transportation Economics, 48, pp. 194-204. doi: https://doi.org/10.1016/j.retrec.2014.09.043.

Suzuki, Hiroaki and Cervero, Robert and luchi, K. (2013) Transforming Cities with Transit:Transit and LandUse Integration for Sustainable Urban Development. The World bank. 